Check for updates

Cite this: Chem. Sci., 2019, 10, 4436

๑ All publication charges for this article have been paid for by the Royal Society of Chemistry

Received 26th July 2018

Accepted 13th March 2019

DOI: $10.1039 / \mathrm{c} 8 \mathrm{sc} 03316 \mathrm{a}$

rsc.li/chemical-science

\section{A donor-chromophore-catalyst assembly for solar $\mathrm{CO}_{2}$ reduction $\uparrow$}

\author{
Degao Wang, $\dot{t}^{\mathrm{a}}$ Ying Wang, $\dot{t}^{\mathrm{a}}$ Matthew D. Brady, ${ }^{a}$ Matthew V. Sheridan, (D) a \\ Benjamin D. Sherman, (D) ${ }^{\mathrm{b}}$ Byron H. Farnum, ${ }^{a}$ Yanming Liu, ${ }^{a}$ Seth L. Marquard, ${ }^{a}$ \\ Gerald J. Meyer, ${ }^{a}$ Christopher J. Dares (D) ${ }^{\mathrm{c}}$ and Thomas J. Meyer (DD *a
}

\begin{abstract}
We describe here the preparation and characterization of a photocathode assembly for $\mathrm{CO}_{2}$ reduction to $\mathrm{CO}$ in $0.1 \mathrm{M} \mathrm{LiClO}_{4}$ acetonitrile. The assembly was formed on $1.0 \mu \mathrm{m}$ thick mesoporous films of $\mathrm{NiO}$ using a layer-by-layer procedure based on $\mathrm{Zr}(\mathrm{IV})$ - phosphonate bridging units. The structure of the $\mathrm{Zr}$ (IV) bridged assembly, abbreviated as $\mathrm{NiO}-\mathrm{DA}-\mathrm{RuCP}_{2}{ }^{2+}-\mathrm{Re}()_{1}$, where $\mathrm{DA}$ is the dianiline-based electron donor $\left(\mathrm{N}, \mathrm{N}, \mathrm{N}^{\prime}, \mathrm{N}^{\prime}-\left(\left(\mathrm{CH}_{2}\right)_{3} \mathrm{PO}_{3} \mathrm{H}_{2}\right)_{4}-4,4^{\prime}\right.$-dianiline), RuCP${ }^{2+}$ is the light absorber $\left[\mathrm{Ru}\left(\left(4,4^{\prime}-\left(\mathrm{PO}_{3} \mathrm{H}_{2} \mathrm{CH}_{2}\right)_{2}-2,2^{\prime}-\right.\right.\right.$ bipyridine)(2,2'-bipyridine $\left.))_{2}\right]^{2+}$, and $\mathrm{Re}(\mathrm{I})$ is the $\mathrm{CO}_{2}$ reduction catalyst, $\mathrm{Re}^{\prime}\left(\left(4,4^{\prime}-\mathrm{PO}_{3} \mathrm{H}_{2} \mathrm{CH}_{2}\right)_{2}-2,2^{\prime}-\right.$ bipyridine) $(\mathrm{CO})_{3} \mathrm{Cl}$. Visible light excitation of the assembly in $\mathrm{CO}_{2}$ saturated solution resulted in $\mathrm{CO}_{2}$ reduction to $\mathrm{CO}$. A steady-state photocurrent density of $65 \mu \mathrm{A} \mathrm{cm}{ }^{-2}$ was achieved under one sun illumination and an IPCE value of $1.9 \%$ was obtained with $450 \mathrm{~nm}$ illumination. The importance of the DA aniline donor in the assembly as an initial site for reduction of the RuCP2+ excited state was demonstrated by an 8 times higher photocurrent generated with DA present in the surface film compared to a control without DA. Nanosecond transient absorption measurements showed that the expected reduced one-electron intermediate, $\mathrm{RuCP}^{+}$, was formed on a sub-nanosecond time scale with back electron transfer to the electrode on the microsecond timescale which competes with forward electron transfer to the $\operatorname{Re}\left(\right.$ I) catalyst at $t_{1 / 2}=2.6 \mu \mathrm{s}\left(k_{\mathrm{ET}}=2.7 \times 10^{5} \mathrm{~s}^{-1}\right)$.
\end{abstract}

\section{Introduction}

In natural photosynthesis, conversion of sunlight and $\mathrm{CO}_{2}$ into chemical fuels integrates light absorption and catalysis. ${ }^{\mathbf{1 - 7}}$ In Dye Sensitized Photoelectrosynthesis Cells (DSPECs) molecular assemblies are integrated with light absorbers and catalysts on electrode surfaces for water splitting or reduction of $\mathrm{CO}_{2} \cdot{ }^{8-12}$ Significant advances have been made in the last ten years developing high efficiency photoanodes for water oxidation and proton reduction, while progress on the development of high photocurrent efficiency photocathodes for $\mathrm{CO}_{2}$ reduction still remains challenging. ${ }^{13-21}$

Due to its chemical significance, many innovative approaches have been developed to advance the photoreduction of $\mathrm{CO}_{2} \cdot{ }^{22-33}$ These studies reflect considerable effort to use abundant minerals as catalysts and light absorbers alongside the long standing issue of developing more efficient

\footnotetext{
${ }^{a}$ Department of Chemistry, University of North Carolina Chapel Hill, Chapel Hill, North Carolina 27599, USA. E-mail: tjmeyer@unc.edu

${ }^{b}$ Department of Chemistry, Texas Christian University, Fort Worth, Texas 76129, USA ${ }^{\circ}$ Department of Chemistry and Biochemistry, Florida International University, 11200 SW Eighth Street, Miami, Florida 33199, USA

$\dagger$ Electronic supplementary information (ESI) available. See DOI: 10.1039/c8sc03316a

\$ These authors contributed equally to this work.
}

components as a whole. Several novel strategies have been utilized for $\mathrm{CO}_{2}$ fixation including biosynthesis, ${ }^{27}$ the use of spongy materials, ${ }^{28}$ and utilization of metal-organicframeworks. ${ }^{31}$

The approach to $\mathrm{CO}_{2}$ reduction using a DSPEC in this work makes use of molecular chromophore and catalyst species adsorbed on a NiO semiconductor electrode. Using this strategy, Ishitani and co-workers have made significant progress in the area of $\mathrm{CO}_{2}$ reduction devices, ${ }^{33,34}$ and related approaches between these and water splitting photoanodes such as the use of tandem cells for unbiased DSPEC operation and development of more effective photoelectrode materials have been advanced in recent years. ${ }^{35,36}$

The key reactions involved in the light-driven $\mathrm{CO}_{2}$ reduction process for this device are summarized in eqn (1)-(3). Excitation of the chromophore (Chrom) by sunlight in eqn (1), results in an excited state which, following excitation and injection, leads to formation of a hole in the semiconductor $\mathrm{NiO}\left(\mathrm{h}^{+}\right)$, and electron transfer to the catalyst, Cat, eqn (2). The latter begins the process of catalyst activation of a cycle for $\mathrm{CO}_{2}$ reduction, eqn (3). The latter reaction is in competition with back electron transfer from the electrode in this device, eqn (4). The final step in the process, to complete the circuit, is conduction of the injected hole to an anode (here, a Pt wire for dark water oxidation), eqn (5). 
Injection

$$
\mathrm{NiO} \mid \text { Chrom-Cat }+h \nu \rightarrow \mathrm{NiO}\left(\mathrm{h}^{+}\right) \mid \operatorname{Chrom}\left(\mathrm{e}^{-}\right)-\mathrm{Cat}
$$

Catalyst activation

$$
\left.\mathrm{NiO}\left(\mathrm{h}^{+}\right)\left|\operatorname{Chrom}\left(\mathrm{e}^{-}\right)-\mathrm{Cat} \rightarrow \mathrm{NiO}\left(\mathrm{h}^{+}\right)\right| \text {Chrom-Cat }^{-} \mathrm{e}^{-}\right)
$$

$\mathrm{CO}_{2}$ reduction step

$$
\begin{aligned}
& \mathrm{NiO}\left(\mathrm{h}^{+}\right) \mid \text {Chrom-Cat }\left(\mathrm{e}^{-}\right)+\mathrm{CO}_{2} \rightarrow \\
& \mathrm{NiO}\left(\mathrm{h}^{+}\right) \mid \text {Chrom- }\left[\text { Cat- } \mathrm{CO}_{2}\right]^{-}
\end{aligned}
$$

Back electron transfer

$$
\mathrm{NiO}\left(\mathrm{h}^{+}\right) \mid \text {Chrom-Cat }\left(\mathrm{e}^{-}\right) \rightarrow \mathrm{NiO} \mid \text { Chrom-Cat }
$$

Anode oxidation

$$
\begin{aligned}
& \mathrm{NiO}\left(\mathrm{h}^{+}\right) \mid \text {Chrom- }\left[\text { Cat- } \mathrm{CO}_{2}\right]^{-}+\operatorname{anode} \rightarrow \\
& \mathrm{NiO} \mid \mathrm{Chrom}-\mathrm{Cat}\left(\mathrm{e}^{-}\right)+\operatorname{anode}\left(\mathrm{h}^{+}\right)
\end{aligned}
$$

However, the collective results of an extensive literature on $\mathrm{NiO}$ based photocathodes have not been promising for practical applications thus far., ${ }^{9,37-45}$ Transient optical experiments have shown that, following excited state injection on NiO, rapid back electron transfer dominates (eqn (4)), resulting in low steady state concentrations of semiconductor holes and low photocurrent efficiencies in the multi-electron reduction of $\mathrm{CO}_{2}$ to $\mathrm{CO}$, eqn (6).

$$
2 \mathrm{H}^{+}+\mathrm{CO}_{2}+2 \mathrm{e}^{-} \rightarrow \mathrm{H}_{2} \mathrm{O}+\mathrm{CO}
$$

In natural photosynthesis, photon excitation and electron transfer catalysis are linked through an assembly of redox active groups that provide a free energy gradient for directed electron and hole transfer. This natural assembly supports electron transfer over long distances which inhibit back electron transfer because of the exponential dependence of outer-sphere electron transfer on distance. ${ }^{\mathbf{4 6 - 4 8}}$ The strategy has not been generally utilized, in part, because of the complexity of adding additional components to the device and a lack of understanding various pathways for electron transfer.

We report here a layer-by-layer preparation and the resulting properties of a chromophore-catalyst assembly for $\mathrm{CO}_{2}$ reduction to $\mathrm{CO}$. The approach also provides spatial control of electron transfer by using an electron-donating dianiline mediator ('Donor'). The assembly was based on a previous report of assembly formation by layer-by-layer synthesis that gave assemblies integrated functional units for light absorption, electron transfer quenching, and catalysis in single molecule arrays. ${ }^{49-54}$ Here, the same procedure was utilized to prepare a $\mathrm{NiO} \mid$-donor-chromophore-catalyst molecular assembly for $\mathrm{CO}_{2}$ reduction in a DSPEC. The complete surface assembly produced sustained photocurrents ( $>45 \mu \mathrm{A} \mathrm{cm}^{-2}$ over 20 minutes), and produced CO with a faradaic efficiency of $85 \%$ under an applied bias of $-0.54 \mathrm{~V}$ vs. NHE.

\section{Experimental}

\section{Materials}

Dry acetonitrile was purchased from Sigma-Aldrich and used as received. All other reagents were purchased from Sigma-Aldrich without further purification. $N, N, N^{\prime}, N^{\prime}-\left(\left(\mathrm{CH}_{2}\right)_{3} \mathrm{PO}_{3} \mathrm{H}_{2}\right) 4,4^{\prime}$-dianiline (DA) was prepared according to the reported literature. ${ }^{55}$ The $\left[\mathrm{Ru}\left(4,4^{\prime}-\left(\mathrm{PO}_{3} \mathrm{H}_{2} \mathrm{CH}_{2}\right)_{2}-2,2^{\prime} \text {-bipyridine }\right)_{2}\left(2,2^{\prime} \text {-bipyridine }\right)_{2}\right]^{2+}$ $\left(\mathrm{RuCP}_{2}{ }^{2+}\right)$ chromophore was made according to previously published procedures. $^{56}$ The Re complex was prepared following the protocol reported by Schreier et al. ${ }^{\mathbf{2 0}}$

\section{Film preparation}

NanoITO. nanoITO films were prepared by using the doctor blade method. In detail, the nanoITO paste was prepared by mixing $0.5 \mathrm{~g}$ hydroxypropyl cellulose (MW 100 000) into 30\% ITO ethanol solution. After stirring for 2 days, the nanoITO solution was deposited on FTO (TEC 15, Hartford Glass, Hartford City, IN) using one layer of Scotch tape as a spacer. The slides were annealed in box oven for 1 hour at $450{ }^{\circ} \mathrm{C}$. The film thickness was estimated as $c a .2 .3 \mu \mathrm{m}$ by profilometry.

NiO mesoporous films. $1.0 \mathrm{~g} \mathrm{NiCl} \cdot 6 \mathrm{H}_{2} \mathrm{O}$ was dissolved in $3 \mathrm{ml}$ water, then $1.0 \mathrm{~g}$ co-polymer F-108 (Sigma) was added followed by the addition of $6.0 \mathrm{~g}$ of ethanol to the mixture. The mixture was stirred until the solution turned clear and allowed to sit for 48 hours, followed by centrifugation at $3000 \mathrm{rpm}$ for $15 \mathrm{~min}$. Following centrifugation the supernatant liquid was doctor-bladed on a thoroughly cleaned FTO glass slides. After drying in air, the slide as were placed in a box oven for $30 \mathrm{~min}$ at $120{ }^{\circ} \mathrm{C}$, and heated to $450{ }^{\circ} \mathrm{C}$ for $30 \mathrm{~min}$. This process was repeated twice to get $c a .1 .0 \mu \mathrm{m}$ thick films.

\section{Surface assembly formation}

$\mathrm{NiO}$ films were first immersed in $0.1 \mathrm{M} \mathrm{HClO}_{4}$ aqueous solutions containing $2 \mathrm{mM}$ of the aromatic donor $N, N, N^{\prime}, N^{\prime}$ $\left(\left(\mathrm{CH}_{2}\right)_{3} \mathrm{PO}_{3} \mathrm{H}_{2}\right)-4,4^{\prime}$-dianiline (DA) for 12 hours. After copious rinsing with $0.1 \mathrm{M} \mathrm{HClO}_{4}$ water, they were dried under $\mathrm{N}_{2}$ and placed in a $5 \mathrm{mM}$ aqueous solution of zirconyl chloride $\left(\mathrm{ZrOCl}_{2}\right)$ with $0.1 \mathrm{M} \mathrm{HClO}_{4}$ for 2 hours. Following a drying cycle under $\mathrm{N}_{2}$, the thin films were further immersed in a $0.1 \mathrm{mM}$ solution of the chromophore $\left[\mathrm{Ru}\left(4,4^{\prime}-\left(\mathrm{PO}_{3} \mathrm{H}_{2} \mathrm{CH}_{2}\right)_{2}-2,2^{\prime} \text {-bipyridine }\right)_{2}\left(2,2^{\prime}\right.\right.$ bipyridine $\left.)_{2}\right]^{2+}\left(\mathrm{RuCP}_{2}{ }^{2+}\right)$ for 12 hours. Surface coordination was followed by rinsing and drying steps and then addition of a second layer of $\mathrm{Zr}(\mathrm{Iv})$. In the final step, the NiO|-DA-Zr(Iv)$\mathrm{RuCP}_{2}{ }^{2+}$ - $\mathrm{Zr}$ (Iv) electrodes were soaked in methanol solutions containing the catalyst, $\operatorname{Re}^{\mathrm{I}}\left(\left(4,4^{\prime}-\mathrm{PO}_{3} \mathrm{H}_{2} \mathrm{CH}_{2}\right) 2-2,2^{\prime}\right.$ bipyridine $(\mathrm{CO})_{3} \mathrm{Cl}$, at $2 \mathrm{mM}$ for 24 hours to give the assembly, $\mathrm{NiO} \mid-\mathrm{DA}-\mathrm{RuCP}_{2}{ }^{2+}$-Re(I).

The control electrode $\mathrm{NiO} \mid-\mathrm{RuCP}_{2}{ }^{2+}-\mathrm{Re}(\mathrm{I})$ was fabricated by immersing NiO films in a $0.1 \mathrm{mM}$ solution of the chromophore $\left[\mathrm{Ru}\left(4,4^{\prime}-\left(\mathrm{PO}_{3} \mathrm{H}_{2} \mathrm{CH}_{2}\right)_{2}-2,2^{\prime} \text {-bipyridine }\right)_{2}\left(2,2^{\prime} \text {-bipyridine }\right)_{2}\right]^{2+}$ $\left(\mathrm{RuCP}_{2}{ }^{2+}\right)$ for 12 hours. Surface coordination was followed by rinsing and drying steps and then the addition of a layer of $\mathrm{Zr}$ (Iv) which was formed by soaking in a $5 \mathrm{mM}$ aqueous solution of $\mathrm{ZrOCl}_{2}$ in $0.1 \mathrm{M} \mathrm{HClO}_{4}$ for 2 hours. In the next step, the NiO|$\mathrm{RuCP}_{2}{ }^{2+}-\mathrm{Zr}$ (Iv) electrodes were soaked in methanol solution 
containing the catalyst, $\mathrm{Re}(\mathrm{I})\left(\left(4,4^{\prime}-\mathrm{PO}_{3} \mathrm{H}_{2} \mathrm{CH}_{2}\right)_{2}-2,2^{\prime}\right.$ bipyridine)(CO) ${ }_{3} \mathrm{Cl}$, at $2 \mathrm{mM}$ for 24 hours to give the assembly, $\mathrm{NiO}-\mathrm{RuCP}_{2}{ }^{2+}-\mathrm{Re}(\mathrm{I})$. The electrode nanoITO|- $\mathrm{RuCP}_{2}{ }^{2+}-\mathrm{Re}(\mathrm{I})$ was made using an identical procedure but with nanoITO replacing the NiO film.

\section{Instrumentation}

UV-visible absorbance measurements were performed using an Agilent Technologies Cary 8454 UV-visible spectrometer.

Scanning electron microscope (SEM) images were obtained on a FEI Helios 600 Nanolab Dual Beam System focused ion beam (FIB) equipped with an Oxford Instruments, INCA PentaFET-x3 X-ray detector with the electron beam set to $2 \mathrm{keV}$ and a beam current of $0.69 \mathrm{nA}$.

XPS spectra were acquired by using a Kratos Axis Ultra DLD $\mathrm{X}$-ray photoelectron spectrometer with a base pressure of $6 \times$ $10^{-9}$ Torr, a monochromatic $\mathrm{Al} \mathrm{K} \alpha \mathrm{X}$-ray source, and an analyzer pass energy of either $80 \mathrm{eV}$ or $20 \mathrm{eV}$ for survey and high resolution scans respectively.

X-ray diffraction were used to characterize the prepared NiO films. A Rigaku SmartLab was utilized which consisted of an Xray source ( $3 \mathrm{~kW} \mathrm{Cu}$ tube) and the detector - a OD scintillation detector.

\section{Gas chromatography}

At the end of a photoelectrochemical experiment, $0.6 \mathrm{~mL}$ of a gaseous sample was taken out of the sealed headspace by a gas tight syringe (Vici) and injected into a gas chromatograph (Varian 450-GC). A temperature gradient program was used starting at $40{ }^{\circ} \mathrm{C}$ which was ramped to $220^{\circ} \mathrm{C}$ at $20^{\circ} \mathrm{C} \mathrm{min}{ }^{-1}$. The calibration curves for $\mathrm{H}_{2}$ and $\mathrm{CO}$ were obtained by using certified standard gas samples obtained from Sigma-Aldrich (SCOTTY gas standards). The column used for GC here was Shin Carbon.

\section{Photoelectrochemical measurements}

Electrochemical and photoelectrochemical measurements were performed by using a $\mathrm{CH}$ Instruments $760 \mathrm{E}$ bipotentiostat. The white light illumination (400 nm cut-off, $100 \mathrm{~mW} \mathrm{~cm} \mathrm{~cm}^{-2}$ ) was provided by a THORLABS HPLS 30-04 light source. Incident photon to current efficiency (IPCE) measurements were performed with a $75 \mathrm{~W}$ xenon lamp (Oriel) and Oriel Cornerstone 260 monochromator. Photocurrent data were taken at $5 \mathrm{~nm}$ increments and the light intensity at each wavelength was recorded by using a UDT S370 optometer coupled to a UDT 260 detector. A $\mathrm{CH}$ Instruments $660 \mathrm{D}$ potentiostat was used to record the photocurrent transients and a bias of $-0.54 \mathrm{~V} v s$. NHE was used during collection of the IPCE data.

\section{Spectroelectrochemical measurements}

Spectroelectrochemical measurements were used to evaluate surface-bound redox potentials and spectral features for transient absorption kinetic analysis. The spectra were modeled from a linear combination of the ground state spectrum and the fully oxidized DA or fully reduced ' $\mathrm{RuCP}_{2}{ }^{+}$' and ' $\mathrm{Re}(0)$ ' intermediates to determine mole fractions of each species at the applied potentials. The potential where equal amounts of the two redox species (neutral and reduced or oxidized) were present was taken as the formal reduction potential. Delta extinction coefficient spectra $(\Delta \varepsilon)$ were calculated with the assumption that the solution extinction coefficients for all the complexes remain the same on the surface.

\section{Steady-state photoluminescence}

Steady spectra were obtained with a HORIBA Fluorolog spectrophotometer equipped with a $450 \mathrm{~W}$ Xe arc lamp for the excitation source. PL spectra were obtained at room temperature with PL detected at a front facing orientation when it contacted a slide. The excitation wavelength for photoluminescence was $450 \mathrm{~nm}$.

\section{Transient absorption}

Nanosecond transient absorption measurements were acquired on a setup described previously. ${ }^{57}$ Briefly, a Q-switched, pulsed Nd:YAG laser (Quantel U.S.A. (BigSky) Brilliant B 5-6 ns full width at half-maximum (fwhm), $1 \mathrm{~Hz}, \sim 10 \mathrm{~mm}$ in diameter) doubled to $532 \mathrm{~nm}$ was passed through an OPO and tuned to $488 \mathrm{~nm}$. The laser irradiance at the sample was attenuated to 4.5 $\mathrm{mJ}$ per pulse. A $150 \mathrm{~W}$ xenon arc probe lamp was pulsed at $1 \mathrm{~Hz}$ with $70 \mathrm{~V}$ during the experiment. Signal detection was achieved using a monochromator (SPEX 1702/04) optically coupled to an R928 photomultiplier tube (Hamamatsu) at a right angle to the excitation laser. Transient data were acquired with a computerinterfaced digital oscilloscope (LeCroy 9450, Dual $330 \mathrm{MHz}$ ) with an overall instrument response time of $\sim 20$ ns. 30 laser pulses were acquired and averaged at each wavelength over the 370-800 nm range. Intervals of $10 \mathrm{~nm}$ were used for wavelengths between 370 and $600 \mathrm{~nm}$ and intervals of $20 \mathrm{~nm}$ were used between 600 and $800 \mathrm{~nm}$.

\section{Results and discussion}

\section{Synthesis and characterization}

Scheme 1 illustrates the components used for the preparation of the surface assembly. Coordination to the surface and assembly formation were based on phosphonate-Zr(Iv) bridges on the surfaces of mesoporous $1.0 \mu \mathrm{m}$ thick films of NiO composed of 15-20 nm diameter NiO particles. ${ }^{58,59}$ SEM and XRD characterization of NiO films are shown in Fig. S1 and S2. $\dagger$ Details on the preparation of the NiO films is provided in the experimental section. The final structure, with the $\mathrm{Zr}(\mathrm{Iv})$ bridging groups, is shown in Scheme 1, with a redox potential diagram shown in Fig. 1.

UV-visible absorption measurements were used to monitor assembly formation. Typical data are illustrated in Fig. 2 for $\mathrm{NiO} \mid-\mathrm{DA}, \mathrm{NiO}-\mathrm{DA}-\mathrm{RuCP}_{2}{ }^{2+}$, and $\mathrm{NiO} \mid-\mathrm{DA}-\mathrm{RuCP}_{2}{ }^{2+}-\mathrm{Re}(\mathrm{I})$. The spectrum of the assembly NiO|-DA-RuCP${ }_{2}{ }^{2+}$ includes a metal-toligand charge-transfer (MLCT) absorption maximum at $460 \mathrm{~nm}$ which corresponds to a region expected for the $\mathrm{Ru}(\mathrm{II})$ chromophore MLCT. In the final assembly, NiO|-DA-RuCP ${ }_{2}{ }^{2+}-\mathrm{Re}(\mathrm{I})$, the absorption spectrum includes an additional feature, the $\mathrm{CO}_{2}$ catalyst, with a MLCT absorption at 350-450 nm. The spectrum 


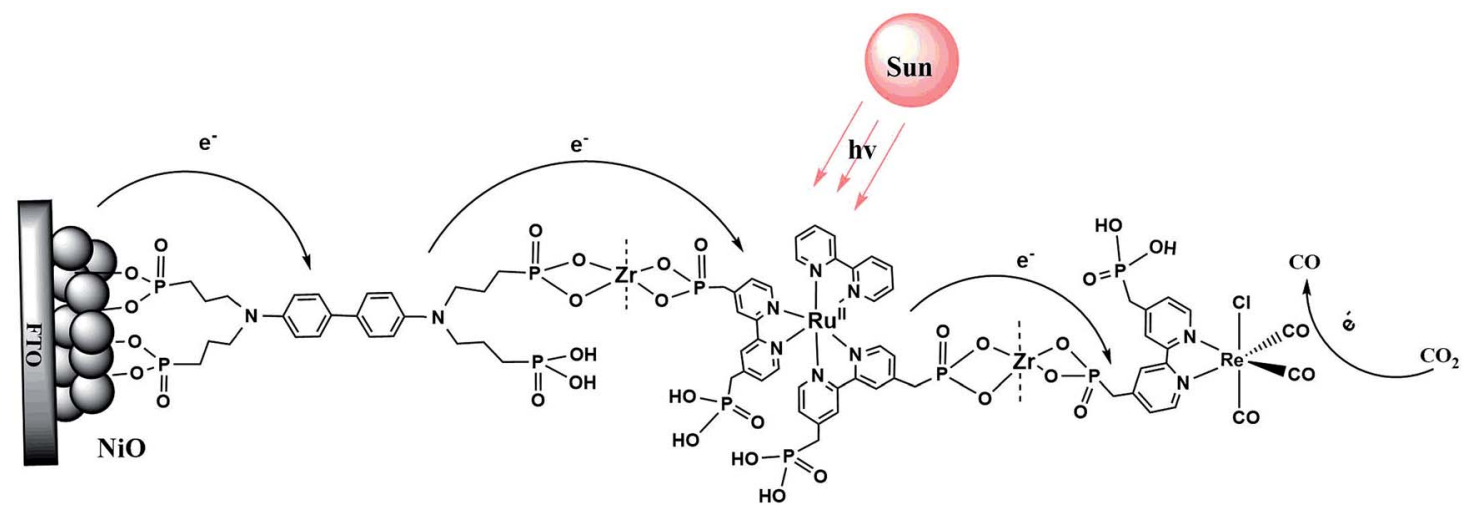

Scheme 1 Structure of the assembly $\mathrm{NiO}-\mathrm{DA}-\mathrm{RuCP}_{2}{ }^{2+}-\mathrm{Re}()^{\prime}$ on a mesoporous $\mathrm{NiO}$ electrode.

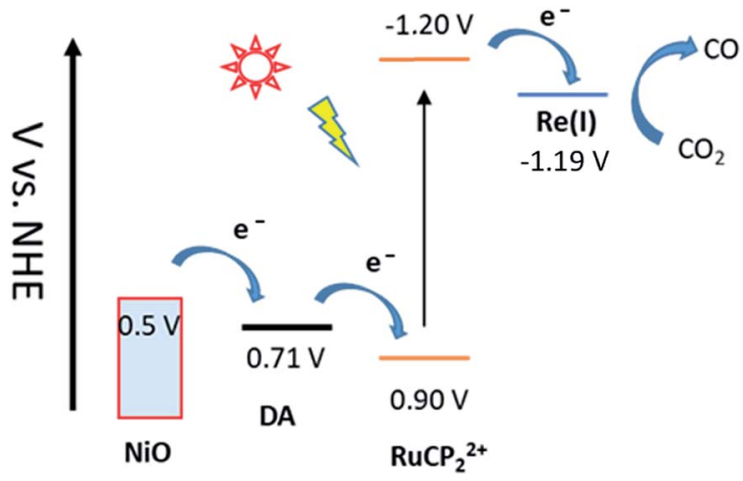

Fig. 1 Redox potential diagram for the assembly, $\mathrm{NiOl}-\mathrm{DA}-\mathrm{RuCP}_{2}{ }^{2+}-$ $\operatorname{Re}()_{1}$, illustrating excitation and stepwise electron transfer following excitation of the $\mathrm{RuCP}_{2}{ }^{2+}$ chromophore.

of the $\operatorname{Re}(\mathrm{I})$ catalyst in methanol solution is shown in Fig. $\mathrm{S} 3 \dagger$ for comparison. Based on the relation $\Gamma=A /(\varepsilon 1000)$, the surface coverage of the chromophore $\mathrm{RuCP}_{2}{ }^{2+}$ was $\Gamma=2 \times 10^{-8} \mathrm{~mol}$ $\mathrm{cm}^{-2}$ at $\varepsilon(460 \mathrm{~nm})=1.39 \times 10^{4} \mathrm{M}^{-1} \mathrm{~cm}^{-1}$ for the $\mathrm{RuCP}^{2+}$ chromophore.

To verify the presence of the catalyst, an XPS spectrum that included Re-based absorptions for $4 f_{5 / 2}$ at $42.8 \mathrm{eV}$ and for $4 \mathrm{f}_{7 / 2}$ at $40.7 \mathrm{eV}$, was obtained with peak energies consistent with literature values, as shown Fig. S4.† According to the elemental analysis of the XPS measurements (data shown in the bottom of Fig. $\mathrm{S} 4 \dagger)$, the ratio of $\mathrm{Re}: \mathrm{Ru}$ in the $\mathrm{NiO}-\mathrm{DA}-\mathrm{RuCP}_{2}{ }^{2+}-\mathrm{Re}$ assembly was approximately $1: 1$, consistent with a $1: 1$ ratio in the final assembly and full surface loading.

For electrochemical measurements, the same preparation procedure was used as described for the assemblies on $\mathrm{NiO}$ surfaces, however, an indium doped tin oxide (nanoITO) substrate was used instead of NiO. Redox properties of the assemblies nanoITO|-DA, nanoITO|- $\mathrm{RuCP}_{2}{ }^{2+}$, and nanoITO|$\operatorname{Re}(\mathrm{I})$, were investigated by spectro-electrochemistry on mesoporous nanoITO films in $0.1 \mathrm{M} \mathrm{LiClO}_{4}$ acetonitile. From the data in Fig. S5 and S6, $\uparrow$ a quasi-reversible, reduction appears at $0.71 \mathrm{~V}$ for the $\mathrm{DA}^{+\cdot / 0}$ couple, at $-1.19 \mathrm{~V}$ for the $-\mathrm{Re}^{\mathrm{I}} /^{0 \cdot}$ couple, and at $-1.20 \mathrm{~V}$ and for the $-\mathrm{RuCP}_{2}{ }^{2+/+}$ couple vs. NHE. The
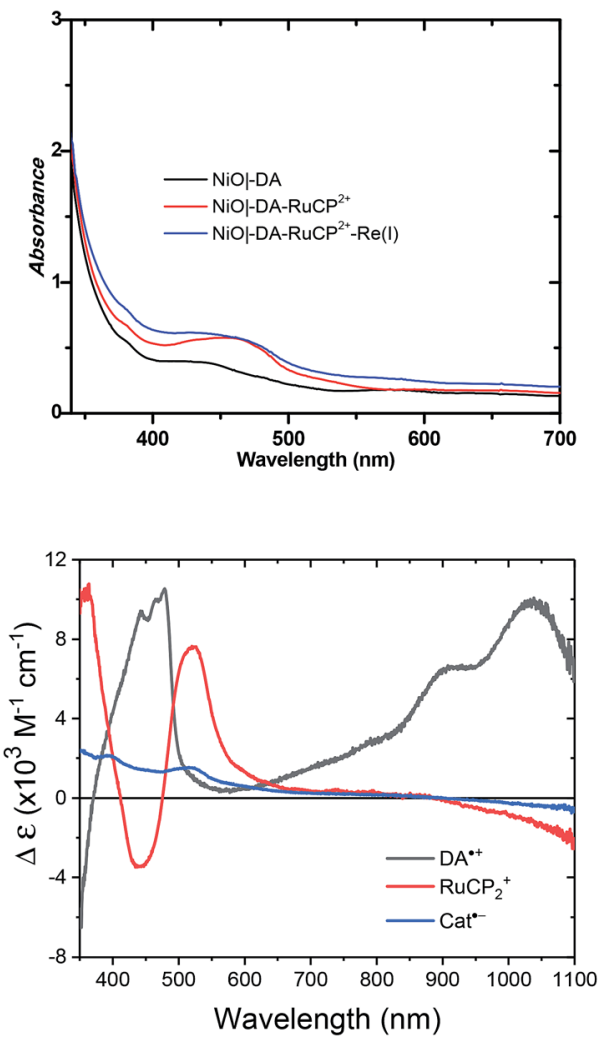

Fig. 2 UV-visible absorption spectra of neutral molecular assemblies on $\mathrm{NiO}$ electrodes measured in air (top), and the corresponding spectra for each oxidized (DA) or reduced $\left(\mathrm{RuCP}_{2}\right.$ or Cat) species obtained by spectroelectrochemistry (bottom).

values of the re-oxide couples are summarized in Table 1. The individual spectra are highlighted at the bottom of Fig. 2.

\section{Photocurrent studies}

The photocurrent responses of $\mathrm{NiO}-\mathrm{RuCP}_{2}{ }^{2+}-\mathrm{Re}(\mathrm{I})$ and $\mathrm{NiO}-$ DA-RuCP ${ }_{2}{ }^{2+}-\mathrm{Re}(\mathrm{I})$ electrodes were studied using a standard three-electrode photoelectrochemical cell with 1 sun illumination (100 mW cm ${ }^{-2}, 400 \mathrm{~nm}$ cutoff filter) in $\mathrm{CO}_{2}$ saturated $0.1 \mathrm{M}$ $\mathrm{LiClO}_{4}$ acetonitrile solution. The working electrodes were $\mathrm{NiO}$ - 
Table 1 Formal reduction potentials ${ }^{a}$

\begin{tabular}{lllll}
\hline Species & $\mathrm{DA}^{+/ 0}$ & $\mathrm{RuCP}_{2}{ }^{2+/+}$ & $\mathrm{RuCP}_{2}{ }^{2+* /+}$ & $\operatorname{Re}(\mathrm{I})$ \\
Couple & $+\% 0$ & $2+/+$ & $2+* /+$ & $1+/ 0^{\circ}$ \\
$E^{\prime}(\mathrm{V})$ & 0.71 & -1.20 & 0.90 & -1.19
\end{tabular}

${ }^{a}$ On nanoITO electrodes, $\mathrm{V} v s$. NHE at room temperature in acetonitrile $0.1 \mathrm{M}$ in $\mathrm{LiClO}_{4}$ measured using a $\mathrm{Ag}^{+} / \mathrm{Ag}$ quasi-reference electrode referenced internally to the ferrocenium/ferrocene couple with $\mathrm{Fc}^{+} / \mathrm{Fc}$ taken as $0.62 \mathrm{~V} v s$. NHE.

$\mathrm{RuCP}_{2}{ }^{2+}-\mathrm{Re}(\mathrm{I})$ or $\mathrm{NiO} \mid-\mathrm{DA}-\mathrm{RuCP}_{2}{ }^{2+}-\mathrm{Re}(\mathrm{I})$ with a platinum wire as the counter electrode and $\mathrm{a} \mathrm{Ag} / \mathrm{Ag}^{+}$quasi-reference electrode. After three $10 \mathrm{~s}$ light on/off cycles, the photocurrent response for $\mathrm{NiO}$-DA-RuCP${ }_{2}{ }^{2+}$-Re(I) was $\sim 65 \mu \mathrm{A} \mathrm{cm}{ }^{-2}$ at the end of each cycle. This photocurrent response was nearly 8 times larger than that measured for an assembly without the DA electron transfer mediator, $\mathrm{NiO}-\mathrm{RuCP}_{2}{ }^{2+}-\mathrm{Re}(\mathrm{I})$, as shown in Fig. 3a. The enhanced photocurrent density with the dianiline donor arises from intra-assembly electron transfer initially from the DA donor to the MLCT excited state of $\mathrm{RuCP}_{2}{ }^{2+} *$, discussed below. Results of a long term photolysis experiment using NiO|-DA$\mathrm{RuCP}_{2}{ }^{2+}$-Re(I) conducted over a 20 min period (Fig. $3 \mathrm{~b}$ ) showed photocurrents for the assembly $\mathrm{NiO} \mid-\mathrm{DA}-\mathrm{RuCP}_{2}{ }^{2+}-\mathrm{Re}(\mathrm{I})$ decreasing by $c a$. $40 \%$ over this time period.

To test for the effect of applied bias, current densities were measured with the bias voltage was scanned from -0.95 to $0.4 \mathrm{~V}$
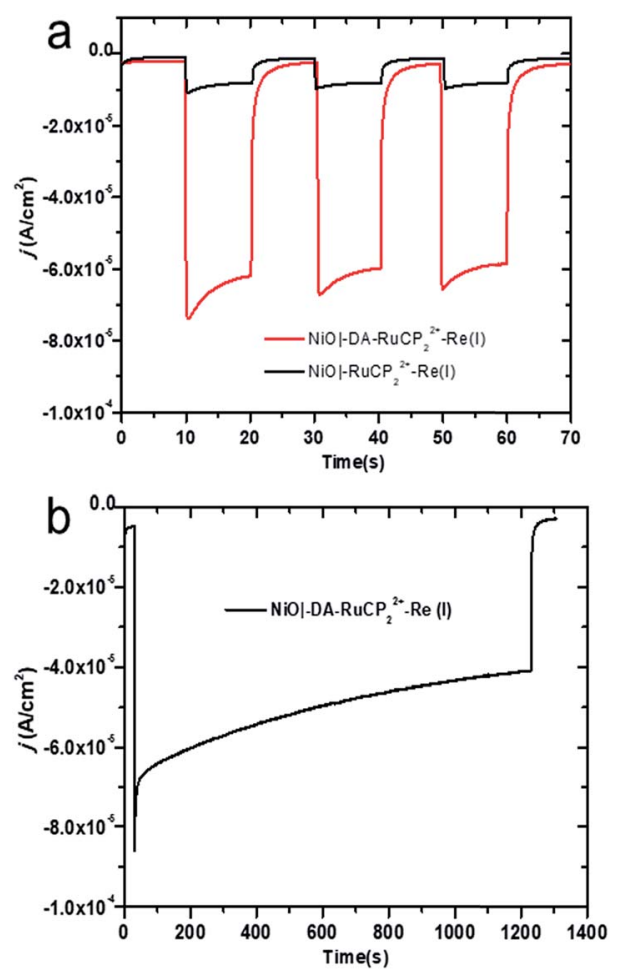

Fig. 3 (a) Photocurrent density versus time $(j-t)$ plots for $\mathrm{NiO}$ assemblies with three $10 \mathrm{~s}$ dark-light (one sun illumination) cycles with

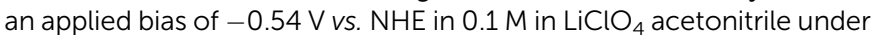
$1 \mathrm{~atm} \mathrm{CO}_{2}$. (b) Photocurrent response of $\mathrm{NiOl}-\mathrm{DA}-\mathrm{RuCP}{ }_{2}{ }^{2+}-\mathrm{Re}(1)$, over a 20 min period under the same conditions as described for (a). vs. NHE under light and dark conditions, Fig. S8. $\dagger$ More negative applied voltages increased the photocurrent density up to the background catalytic wave starting at $c a$. $-0.8 \mathrm{~V}$. As a note, there was no evidence for background catalytic behavior toward $\mathrm{CO}_{2}$ reduction by $\mathrm{NiO}$-DA-RuCP${ }_{2}{ }^{2+}$ - $\mathrm{Re}(\mathrm{I})$ until an applied bias of $-0.8 \mathrm{~V} v s$. NHE was reached under dark conditions. When illuminated, the $\mathrm{NiO} \mid-\mathrm{DA}-\mathrm{RuCP}_{2}{ }^{2+}-\mathrm{Re}(\mathrm{I})$ photocathode maintained in cathodic current up to a bias of $-0.1 \mathrm{~V} v s$. NHE, $0.7 \mathrm{~V}$ more positive than the electrocatalytic onset potential. For comparison, the same experiments were carried out with the assembly $\mathrm{NiO} \mid-\mathrm{RuCP}_{2}{ }^{2+}$ - $\mathrm{Re}(\mathrm{I})$ under dark and light conditions in $\mathrm{CO}_{2}$ saturated $0.1 \mathrm{M} \mathrm{NaClO}_{4}$ acetonitrile solution as shown in Fig. S9. $\dagger$ While the surface still showed a photocathodic response, the photocurrent density was substantially lower as compared to the full assembly containing the DA unit (Fig. S8 $\dagger$ ), consistent with Fig. 3a. As noted above, the photocurrent density obtained at the DA assembly represents significant improvement over the electrode without the electron mediator, $\mathrm{NiO}-\mathrm{RuCP}_{2}{ }^{2+}-\mathrm{Re}(\mathrm{I})$. Enhancements in the photocurrent can be largely attributed to better local charge separation and reduced back electron transfer with the added dianiline donor.

Incident photon-to-current efficiency (IPCE) measurements as a function of excitation wavelength are shown in Fig. S10. $\dagger$ The IPCE value for the assembly NiO|-DA-RuCP ${ }_{2}{ }^{2+}-\mathrm{Re}(\mathrm{I})$ was obtained at an applied bias of $-0.54 \mathrm{~V}$ versus $\mathrm{NHE}$ in $\mathrm{CO}_{2}$ saturated $0.1 \mathrm{M} \mathrm{NaClO}_{4}$ acetonitrile solution. The IPCE profiles overlap with the MLCT absorption profile for the chromophore, as expected for dye-sensitized $\mathrm{CO}_{2}$ reduction. From Fig. S10, $\dagger$ the IPCE value for the assembly, NiO|-DA-RuCP ${ }_{2}{ }^{2+}-\mathrm{Re}(\mathrm{I})$, was $1.9 \%$ at the absorption maximum for the $\mathrm{RuCP}_{2}{ }^{2+}$ chromophore at $450 \mathrm{~nm}$.

\section{Product analysis}

Gas chromatography (GC) was used to estimate faradaic efficiencies for $\mathrm{CO}_{2}$ reduction to $\mathrm{CO}$ for both $\mathrm{NiO}-\mathrm{RuCP}_{2}{ }^{2+}-\mathrm{Re}(\mathrm{I})$ and $\mathrm{NiO} \mid-\mathrm{DA}-\mathrm{RuCP}_{2}{ }^{2+}-\mathrm{Re}(\mathrm{I})$. GC analysis revealed that $\mathrm{CO}$ was the major product for both assemblies as shown in Fig. 4. From the data in Fig. 4, the appearance of $\mathrm{CO}$ for $\mathrm{NiO}-\mathrm{DA}-\mathrm{RuCP}_{2}{ }^{2+}$ $\operatorname{Re}(\mathrm{I})$, as a product of $\mathrm{CO}_{2}$ reduction, is considerably enhanced compared to $\mathrm{NiO} \mid-\mathrm{RuCP}_{2}{ }^{2+}-\mathrm{Re}(\mathrm{I})$. For the latter, the ratio of $\mathrm{H}_{2}$ to CO was $1: 3$ and for the former (assembly with DA), the ratio of $\mathrm{H}_{2}$ to $\mathrm{CO}$ was $1: 8$.

The product distribution for $\mathrm{NiO} \mid-\mathrm{DA}-\mathrm{RuCP}_{2}{ }^{2+}-\mathrm{Re}(\mathrm{I})$ was also investigated as a function of applied potential. At $-0.54 \mathrm{~V} \mathrm{NHE}$, the ratio of $\mathrm{CO}$ to $\mathrm{H}_{2}$ increased nearly to $30: 1$ with concurrent increase in the faradaic efficiency for $\mathrm{CO}$ production to $85 \%$ with $3 \% \mathrm{H}_{2}$ production. The turnover number (TON) for $\mathrm{CO}_{2}$ reduction from this experiment was calculated by comparing it to the number of adsorbed catalyst species and a TON of 22 was obtained with a bias of $-0.54 \mathrm{~V}$ vs. NHE during $20 \mathrm{~min}$ measurements. By further increasing or decreasing the bias from $-0.54 \mathrm{~V}$, CO production was decreased.

\section{Transient absorption}

Interfacial, light-induced electron transfer dynamics were investigated by nanosecond transient absorption measurements 

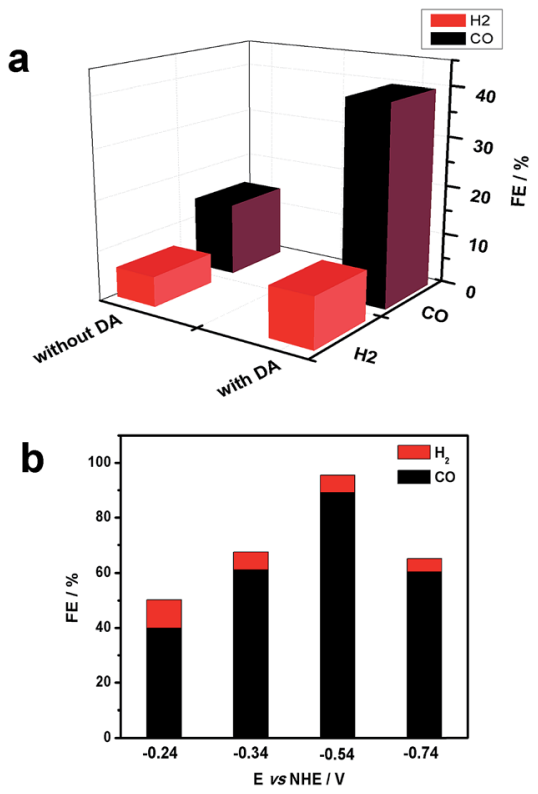

Fig. 4 (a) Analysis of $\mathrm{CO}_{2}$ reduction products following excitation of $\mathrm{NiOl}-\mathrm{RuCP}_{2}{ }^{2+}-\mathrm{Re}\left(\right.$ () with $100 \mathrm{~mW} \mathrm{~cm}^{-2}$ white light source with a bias of $-0.24 \mathrm{~V}$ vs. $\mathrm{NHE}$ in $\mathrm{CO}_{2}$ saturated $0.1 \mathrm{M} \mathrm{LiClO}_{4}$ acetonitrile. (b) Photoelectrochemical $\mathrm{CO}_{2}$ reduction products for same materials as a function of applied bias.

on $\mathrm{NiO} \mid-\mathrm{DA}-\mathrm{RuCP}_{2}{ }^{2+}$-Re(I) and $\mathrm{NiO} \mid-\mathrm{DA}-\mathrm{RuCP}_{2}{ }^{2+}$. Samples were excited with pulsed $488 \mathrm{~nm}$ excitation (4.5 mJ per pulse) in argon-saturated $0.1 \mathrm{M} \mathrm{LiClO}_{4}$ acetonitrile solutions with an applied bias of $-0.8 \mathrm{~V}$ vs. NHE. As shown in Fig. 5, transient absorption difference spectra measured after pulsed laser excitation revealed the prompt appearance of a band near $520 \mathrm{~nm}$ and an absorption edge that increased into the UV region.

$$
\begin{aligned}
& \mathrm{NiO} \mid-\mathrm{DA}-\mathrm{RuCP}_{2}{ }^{2+} * \rightarrow \mathrm{NiO}-\mathrm{DA}^{++}-\mathrm{RuCP}_{2}{ }^{+} \\
& \mathrm{NiO}-\mathrm{DA}^{\cdot+}-\mathrm{RuCP}_{2}{ }^{+} \rightarrow \mathrm{NiO}\left(\mathrm{h}^{+}\right) \mid-\mathrm{DA}^{\cdot+}-\mathrm{RuCP}_{2}{ }^{+} \\
& \mathrm{NiO}\left(\mathrm{h}^{+}\right)\left|-\mathrm{DA}-\mathrm{RuCP}_{2}{ }^{+} \rightarrow \mathrm{NiO}\right|-\mathrm{DA}-\mathrm{RuCP}_{2}{ }^{2+} \\
& \mathrm{NiO}\left|-\mathrm{DA}-\mathrm{RuCP}_{2}{ }^{2+}+h \nu \rightarrow \mathrm{NiO}\left(\mathrm{h}^{+}\right)\right|-\mathrm{DA}-\mathrm{RuCP}_{2}{ }^{+}
\end{aligned}
$$

For NiO|-DA-RuCP ${ }_{2}^{2+}$, excitation of the chromophore results in rapid $\left(k>10^{8} \mathrm{~s}^{-1}\right)$ intra-assembly quenching to give $\mathrm{NiO}$ $\mathrm{DA}^{\cdot+}-\mathrm{RuCP}_{2}{ }^{+}$, eqn (7), and, subsequent electron transfer to $\mathrm{NiO}\left(\mathrm{h}^{+}\right) \mid-\mathrm{DA}-\mathrm{RuCP}_{2}^{+}$(eqn (8)) after hole injection into NiO. The overall conversion to the final surface-assembly-based redox state is summarized in eqn (8), with back electron transfer a competing reaction, eqn (9). The initial electron transfer quenching by the dianiline, eqn (7), is favored by $0.19 \mathrm{~V}$, and is not observed experimentally. Based on these results, and the 20 ns instrument response time, the rate constants for both the electron transfer from DA to $\mathrm{RuCP}_{2}{ }^{2+*}$ and from $\mathrm{NiO}$ to $\mathrm{DA}^{*+}$ are assumed to be $>10^{8} \mathrm{~s}^{-1}$.

As shown by the data in Fig. 6, extension of the transient absorption measurements to $\mathrm{NiO}-\mathrm{DA}-\mathrm{RuCP}_{2}{ }^{2+}$ - $\mathrm{Re}(\mathrm{I})$ gave comparable results. Analysis of time-dependent data at $530 \mathrm{~nm}$
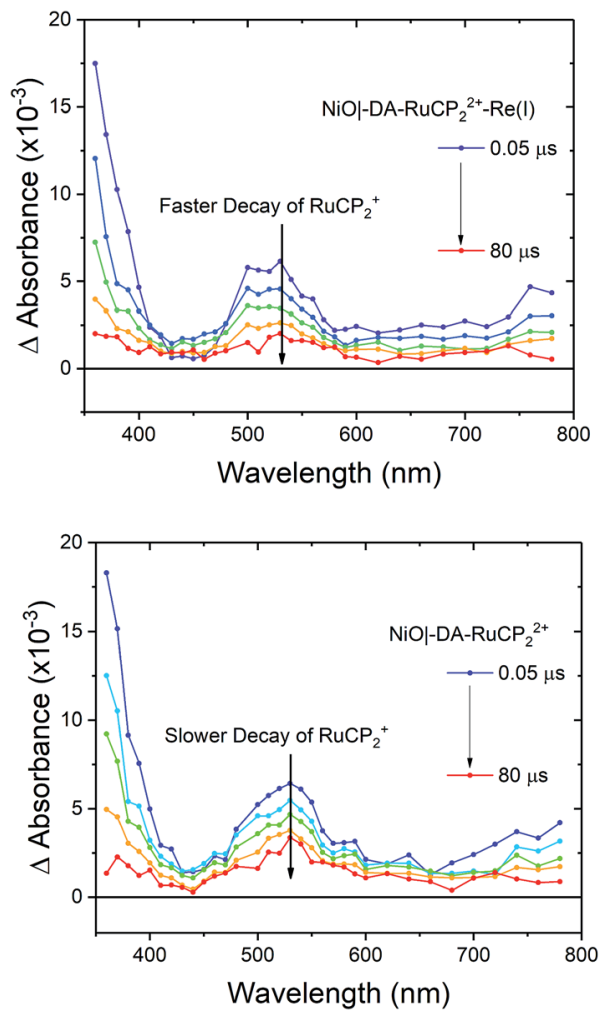

Fig. 5 Nanosecond transient absorption difference spectra measured after pulsed $488 \mathrm{~nm}$ light excitation of $\mathrm{NiO}-\mathrm{DA}-\mathrm{RuCP}_{2}{ }^{2+}-\mathrm{Re}(\mathrm{I})$ (top) and $\mathrm{NiOl}-\mathrm{DA}-\mathrm{RuCP}_{2}{ }^{2+}$ (bottom) in $0.1 \mathrm{M} \mathrm{LiClO}_{4}$ acetonitrile with $-0.8 \mathrm{~V}$ vs. NHE applied potential under argon.

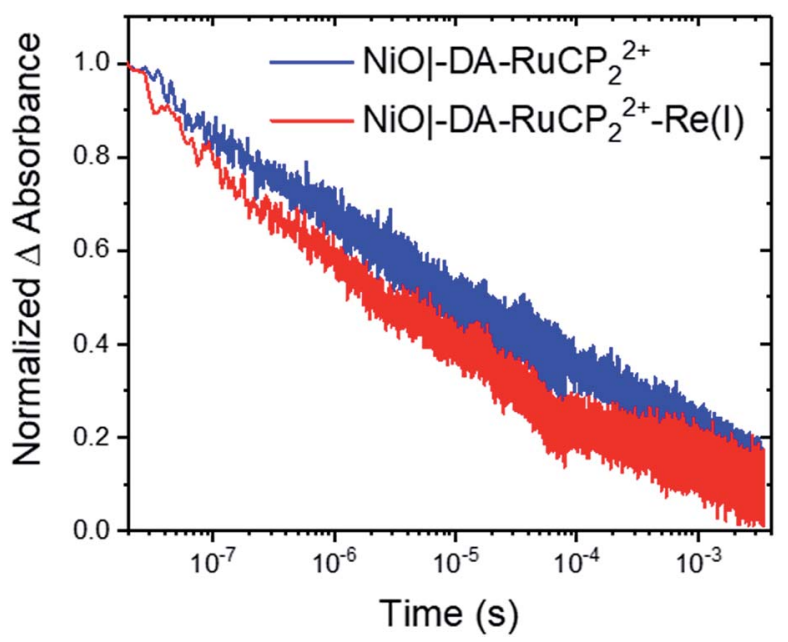

Fig. 6 Normalized transient absorption changes measured at $530 \mathrm{~nm}$ after pulsed $488 \mathrm{~nm}$ excitation of $\mathrm{NiOl}-\mathrm{DA}-\mathrm{RuCP}_{2}{ }^{2+}$ (blue) and $\mathrm{NiOl}-$ $\mathrm{DA}-\mathrm{RuCP}_{2}{ }^{2+}-\mathrm{Re}($ () (red) at $-0.8 \mathrm{~V}$ vs. NHE in argon-saturated $0.1 \mathrm{M}$ $\mathrm{LiClO}_{4}$ acetonitrile solution.

showed that the kinetics of back electron transfer were nonexponential for both assemblies. The kinetics were characterized by the half time for the distribution, $t_{1 / 2}$, the time at which the signal has decreased to half of its original amplitude. For the traces shown in Fig. 6, with the $\operatorname{Re}(\mathrm{I})$ catalyst, $\mathrm{NiO}\left(\mathrm{h}^{+}\right) \mid-\mathrm{DA}-$ 
$\mathrm{RuCP}_{2}{ }^{+}$-Re(I), $t_{1 / 2}$ was $\sim 2.0 \mu$ s. For $\mathrm{NiO}\left(\mathrm{h}^{+}\right) \mid-\mathrm{DA}-\mathrm{RuCP}_{2}{ }^{+}, t_{1 / 2}$ was $8.5 \mu \mathrm{s}$. It is notable that the lifetime for the $\mathrm{NiO}\left(\mathrm{h}^{+}\right) \mid-\mathrm{DA}-\mathrm{RuCP}_{2}{ }^{+}-$ $\operatorname{Re}(\mathrm{I})$ precursor decreased by a factor of $c a$. 4 compared to $\mathrm{NiO}\left(\mathrm{h}^{+}\right) \mid-\mathrm{DA}-\mathrm{RuCP}_{2}{ }^{+}$. This is consistent with electron transfer from $\operatorname{RuCP}_{2}{ }^{+}$to $\operatorname{Re}(\mathrm{I})$, eqn (11).

Next, to calculate the kinetic rate constant for electron transfer in eqn (11), the difference in the loss of $\mathrm{RuCP}^{+}$signal in the catalyst assembly can be attributed to either back electron transfer to $\mathrm{NiO}\left({ }^{\mathrm{h}+}\right)$ or electron transfer to the catalyst. Assuming the rate of back electron transfer is unchanged in the catalyst assembly, the equation for the rate constant is $k_{(\text {eqn (11)) }}=\ln 2(1 /$ $\left.t_{1 / 2, \mathrm{~A}}+1 / t_{1 / 2, \mathrm{~B}}\right)$; where $t_{1 / 2, \mathrm{~A}}$ and $t_{1 / 2, \mathrm{~A}}$ are the two $t_{1 / 2}$ obtained thus far. The calculated rate constant for eqn (11), $k_{(\text {eqn (11)) }}$ or $k_{\mathrm{ET}}$, is therefore $3.7 \times 10^{5} \mathrm{~s}^{-1}\left(t_{1 / 2 \text {,eqn (11) }}=2.6 \mu \mathrm{s}\right)$. In comparable $\mathrm{Zr}$ (Iv) assemblies for light-driven water oxidation, hole transfer occurs with a half-life of 170 ps or $0.00017 \mu \mathrm{s}\left(k_{\mathrm{ET}}=5.9\right.$ $\left.\times 10^{9} \mathrm{~s}^{-1}\right) .{ }^{60}$ The order of magnitude more sluggish electron transfer behaviour for transfer to the $\mathrm{Re}(\mathrm{I})$ catalyst is attributable to the $0.01 \mathrm{eV}$ driving force for the reaction in eqn (11).

$$
\mathrm{NiO}\left|-\mathrm{DA}-\mathrm{RuCP}_{2}{ }^{+}-\mathrm{Re}(\mathrm{I}) \rightarrow \mathrm{NiO}\right|-\mathrm{DA}-\mathrm{RuCP}_{2}{ }^{2+}-\mathrm{Re}(0)
$$

\section{Mechanism}

Insight into the mechanism for $\mathrm{CO}_{2}$ reduction to $\mathrm{CO}$ from the transient absorption experiments is limited by back electron transfer to the electrode. On the timescale of the nanosecond experiments, there is significant kinetic competition between back electron transfer and the rate of activation of the $\operatorname{Re}(\mathrm{I})$ catalyst without additional insight into the mechanism of $\mathrm{CO}_{2}$ reduction.

There is an extensive mechanistic background in this area based on previous studies of $\mathrm{Re}(\mathrm{I})$ catalyst analogs in solution and as a component in assemblies with $\mathrm{Ru}(\mathrm{II})$ polypyridyl complexes. ${ }^{61-63}$ Eqn (12) and (13) summarize the initial mechanistic steps. In the overall mechanism, the catalytic cycle is initiated by visible light absorption by the MLCT chromophore, $-\mathrm{RuCP}_{2}{ }^{2+}$-, to give the MLCT excited state, $-\mathrm{RuCP}_{2}{ }^{2+}{ }_{-}$. Formation of the excited state is followed by its reduction by electron transfer from -DA- and electron transfer from the electrode to DA to give $-\mathrm{RuCP}_{2}{ }^{+}$- and $\mathrm{NiO}(\mathrm{h}+)$. As shown in eqn (13), further electron transfer from the reduced chromophore occurs to the catalyst on the sub-ms timescale.

$$
\begin{gathered}
\mathrm{NiO}\left|-\mathrm{DA}-\mathrm{RuCP}_{2}{ }^{+}-\mathrm{Re}(\mathrm{I})+h \nu \rightarrow \mathrm{NiO}\left(\mathrm{h}^{+}\right)\right|-\mathrm{DA}-\mathrm{RuCP}_{2}{ }^{+}-\mathrm{Re}(\mathrm{I})(12) \\
\mathrm{NiO}\left(\mathrm{h}^{+}\right)\left|-\mathrm{DA}-\mathrm{RuCP}_{2}{ }^{+}-\mathrm{Re}(\mathrm{I}) \rightarrow \mathrm{NiO}\right|-\mathrm{DA}-\mathrm{RuCP}_{2}{ }^{2+}-\mathrm{Re}(0)
\end{gathered}
$$

\section{Conclusions}

We have successfully demonstrated here the synthesis, characterization, and properties of a surface-bound assembly for $\mathrm{CO}_{2}$ reduction to $\mathrm{CO}$ on the surface of mesoporous $\mathrm{NiO}$ electrodes. Formation of the electrode followed from a stepwise assembly synthesis based on phosphonate-Zr(Iv) bridged structures to give the electrode, $\mathrm{NiO}-\mathrm{DA}-\mathrm{RuCP}_{2}{ }^{2+}-\mathrm{Re}(\mathrm{I})$.
Compared to the assembly, $\mathrm{NiO} \mid-\mathrm{RuCP}_{2}{ }^{2+}-\mathrm{Re}(\mathrm{I})$, addition of the -DA- aniline donor was found to accelerate the catalytic effect by a factor of 8 by initial reduction of the MLCT excited state, $-\mathrm{RuCP}_{2}{ }^{2+}$, by the dianiline electron-donating mediator. With 1 sun illumination, photocurrents of up to $65 \mu \mathrm{A} \mathrm{cm}{ }^{-2}$ were obtained for $\mathrm{NiO} \mid-\mathrm{DA}-\mathrm{RuCP}_{2}{ }^{2+}$ - $\mathrm{Re}(\mathrm{I})$ for $\mathrm{CO}_{2}$ reduction to $\mathrm{CO}$ under an atmosphere of $\mathrm{CO}_{2}$ in acetonitrile as the solvent.

Nanosecond transient absorption measurements have been used to show that, in the assembly, initial excitation of the chromophore is followed by rapid, electron transfer to gives intermediate, $\mathrm{NiO}\left(\mathrm{h}^{+}\right) \mid-\mathrm{DA}-\mathrm{RuCP}_{2}{ }^{+}-\mathrm{Re}(\mathrm{I})$. This state undergoes back electron transfer on timescales shorter than a millisecond. Although not directly observed in the transient experiments, with an applied bias, reduction of the catalyst appears to be followed by a sequence of reactions that activate the catalyst toward $\mathrm{CO}_{2}$ reduction. Collectively the data show that a layer-bylayer synthetic approach can be utilized to spatially organize electron donors, catalysts, and chromophores on NiO surfaces for applications in solar fuel production.

\section{Conflicts of interest}

There are no conflicts to declare.

\section{Acknowledgements}

This research was primarily supported by the UNC EFRC: Center for Solar Fuels, an Energy Frontier Research Center funded by the U.S. Department of Energy, Office of Science, Office of Basic Energy Sciences, under Award No. DE-SC0001011, GC and transient absorption experiments (Y. W., M. D. B., S. L. M.). Photoelectrochemical $\mathrm{CO}_{2}$ reduction was provided by D. W., supported by the U.S. Department of Energy (DOE), Nuclear Energy University Program award, under Contract DENE0008539. This work made use of instrumentation at the Chapel Hill Analytical and Nanofabrication Laboratory (CHANL), a member of the North Carolina Research Triangle Nanotechnology Network (RTNN), which is supported by the National Science Foundation (Grant ECCS-1542015) as part of the National Nanotechnology Coordinated Infrastructure (NNCI).

\section{References}

1 J. Barber, Chem. Soc. Rev., 2009, 38, 185-196.

2 N. S. Lewis and D. G. Nocera, Proc. Natl. Acad. Sci. U. S. A., 2006, 103, 15729.

3 D. A. LaVan and J. N. Cha, Proc. Natl. Acad. Sci. U. S. A., 2006, 103, 5251.

4 K. K. Sakimoto, N. Kornienko and P. Yang, Acc. Chem. Res., 2017, 50, 476-481.

5 M. Aresta, A. Dibenedetto and A. Angelini, Chem. Rev., 2014, 114, 1709-1742.

6 G. F. Moore and G. W. Brudvig, Annu. Rev. Condens. Matter Phys., 2011, 2, 303-327.

7 X. Liu, S. Inagaki and J. Gong, Angew. Chem., 2016, 55, 1492414950. 
8 T. J. Meyer, Acc. Chem. Res., 1989, 22, 163-170.

9 G. Sahara, R. Abe, M. Higashi, T. Morikawa, K. Maeda, Y. Ueda and O. Ishitani, Chem. Commun., 2015, 51, 1072210725.

10 D. Wang, B. D. Sherman, B. H. Farnum, M. V. Sheridan, S. L. Marquard, M. S. Eberhart, C. J. Dares and T. J. Meyer, Proc. Natl. Acad. Sci., 2017, 114, 9809-9813.

11 M. K. Brennaman, R. J. Dillon, L. Alibabaei, M. K. Gish, C. J. Dares, D. L. Ashford, R. L. House, G. J. Meyer, J. M. Papanikolas and T. J. Meyer, J. Am. Chem. Soc., 2016, 138, 13085-13102.

12 N. Kaeffer, J. Massin, C. Lebrun, O. Renault, M. ChavarotKerlidou and V. Artero, J. Am. Chem. Soc., 2016, 138, 12308-12311.

13 D. Wang, S. L. Marquard, L. Troian-Gautier, M. V. Sheridan, B. D. Sherman, Y. Wang, M. S. Eberhart, B. H. Farnum, C. J. Dares and T. J. Meyer, J. Am. Chem. Soc., 2018, 140, 719-726.

14 Y. Kou, S. Nakatani, G. Sunagawa, Y. Tachikawa, D. Masui, T. Shimada, S. Takagi, D. A. Tryk, Y. Nabetani, H. Tachibana and H. Inoue, J. Catal., 2014, 310, 57-66.

15 A. Bachmeier, S. Hall, S. W. Ragsdale and F. A. Armstrong, J. Am. Chem. Soc., 2014, 136, 13518-13521.

16 M. Abdellah, A. M. El-Zohry, L. J. Antila, C. D. Windle, E. Reisner and L. Hammarström, J. Am. Chem. Soc., 2017, 139, 1226-1232.

17 P. Xu, N. S. McCool and T. E. Mallouk, Nano Today, 2017, 14, 42-58.

18 M. D. Brady, R. N. Sampaio, D. Wang, T. J. Meyer and G. J. Meyer, J. Am. Chem. Soc., 2017, 139, 15612-15615.

19 F. Li, K. Fan, B. Xu, E. Gabrielsson, Q. Daniel, L. Li and L. Sun, J. Am. Chem. Soc., 2015, 137, 9153-9159.

20 M. Schreier, J. Luo, P. Gao, T. Moehl, M. T. Mayer and M. Grätzel, J. Am. Chem. Soc., 2016, 138, 1938-1946.

21 R. Kamata, H. Kumagai, Y. Yamazaki, G. Sahara and O. Ishitani, ACS Appl. Mater. Interfaces, 2019, 11, 5632-5641.

22 H. Rao, L. C. Schmidt, J. Bonin and M. Robert, Nature, 2017, 548, 74.

23 M. F. Kuehnel, C. D. Sahm, G. Neri, J. R. Lee, K. L. Orchard, A. J. Cowan and E. Reisner, Chem. Sci., 2018, 9, 2501-2509.

24 G. A. Ozin, Adv. Mater., 2015, 27, 1957-1963.

25 J. L. White, M. F. Baruch, J. E. Pander, Y. Hu, I. C. Fortmeyer, J. E. Park, T. Zhang, K. Liao, J. Gu, Y. Yan, T. W. Shaw, E. Abelev and A. B. Bocarsly, Chem. Rev., 2015, 115, 1288812935.

26 R. Francke, B. Schille and M. Roemelt, Chem. Rev., 2018, 118, 4631-4701.

27 C. Liu, B. C. Colón, M. Ziesack, P. A. Silver and D. G. Nocera, Science, 2016, 352, 1210-1213.

28 K. Niu, Y. Xu, H. Wang, R. Ye, H. L. Xin, F. Lin, C. Tian, Y. Lum, K. C. Bustillo, M. M. Doeff, M. T. M. Koper, J. Ager, R. Xu and H. Zheng, Sci. Adv., 2017, 3, e1700921.

29 J. Shen, R. Kortlever, R. Kas, Y. Y. Birdja, O. Diaz-Morales, Y. Kwon, I. Ledezma-Yanez, K. J. P. Schouten, G. Mul and M. T. M. Koper, Nat. Commun., 2015, 6, 8177.

30 C. Costentin, S. Drouet, M. Robert and J.-M. Savéant, Science, 2012, 338, 90.
31 N. Kornienko, Y. Zhao, C. S. Kley, C. Zhu, D. Kim, S. Lin, C. J. Chang, O. M. Yaghi and P. Yang, J. Am. Chem. Soc., 2015, 137, 14129-14135.

32 K. M. Choi, D. Kim, B. Rungtaweevoranit, C. A. Trickett, J. T. D. Barmanbek, A. S. Alshammari, P. Yang and O. M. Yaghi, J. Am. Chem. Soc., 2017, 139, 356-362.

33 Y. Tamaki and O. Ishitani, ACS Catal., 2017, 7, 3394-3409.

$34 \mathrm{H}$. Takeda, C. Cometto, O. Ishitani and M. Robert, ACS Catal., 2017, 7, 70-88.

35 B. D. Sherman, M. V. Sheridan, K.-R. Wee, S. L. Marquard, D. Wang, L. Alibabaei, D. L. Ashford and T. J. Meyer, J. Am. Chem. Soc., 2016, 138, 16745-16753.

36 H. Kumagai, G. Sahara, K. Maeda, M. Higashi, R. Abe and O. Ishitani, Chem. Sci., 2017, 8, 4242-4249.

37 A. Bachmeier, V. C. C. Wang, T. W. Woolerton, S. Bell, J. C. Fontecilla-Camps, M. Can, S. W. Ragsdale, Y. S. Chaudhary and F. A. Armstrong, J. Am. Chem. Soc., 2013, 135, 15026-15032.

38 G. Sahara, H. Kumagai, K. Maeda, N. Kaeffer, V. Artero, M. Higashi, R. Abe and O. Ishitani, J. Am. Chem. Soc., 2016, 138, 14152-14158.

39 E. A. Gibson, Chem. Soc. Rev., 2017, 46, 6194-6209.

40 D. Dini, Y. Halpin, J. G. Vos and E. A. Gibson, Coord. Chem. Rev., 2015, 304-305, 179-201.

41 F. Odobel, Y. Pellegrin, E. A. Gibson, A. Hagfeldt, A. L. Smeigh and L. Hammarström, Coord. Chem. Rev., 2012, 256, 2414-2423.

42 L. D'Amario, L. J. Antila, B. Pettersson Rimgard, G. Boschloo and L. Hammarström, J. Phys. Chem. Lett., 2015, 6, 779-783.

43 E. A. Gibson, A. L. Smeigh, L. Le Pleux, L. Hammarström, F. Odobel, G. Boschloo and A. Hagfeldt, J. Phys. Chem. C, 2011, 115, 9772-9779.

44 M. Gennari, F. Légalité, L. Zhang, Y. Pellegrin, E. Blart, J. Fortage, A. M. Brown, A. Deronzier, M.-N. Collomb, M. Boujtita, D. Jacquemin, L. Hammarström and F. Odobel, J. Phys. Chem. Lett., 2014, 5, 2254-2258.

45 A. M. Brown, L. J. Antila, M. Mirmohades, S. Pullen, S. Ott and L. Hammarström, J. Am. Chem. Soc., 2016, 138, 80608063.

46 D. Gust, T. A. Moore and A. L. Moore, Acc. Chem. Res., 2009, 42, 1890-1898.

47 F. Wen and C. Li, Acc. Chem. Res., 2013, 46, 2355-2364.

48 Y. Zhao, J. R. Swierk, J. D. Megiatto, B. Sherman, W. J. Youngblood, D. Qin, D. M. Lentz, A. L. Moore, T. A. Moore, D. Gust and T. E. Mallouk, Proc. Natl. Acad. Sci. U. S. A., 2012, 109, 15612.

49 M. A. Gross, C. E. Creissen, K. L. Orchard and E. Reisner, Chem. Sci., 2016, 7, 5537-5546.

50 K. Hanson, D. A. Torelli, A. K. Vannucci, M. K. Brennaman, H. Luo, L. Alibabaei, W. Song, D. L. Ashford, M. R. Norris, C. R. K. Glasson, J. J. Concepcion and T. J. Meyer, Angew. Chem., 2012, 51, 12782-12785.

51 D. Wang, M. V. Sheridan, B. Shan, B. H. Farnum, S. L. Marquard, B. D. Sherman, M. S. Eberhart, A. Nayak, C. J. Dares, A. K. Das, R. M. Bullock and T. J. Meyer, J. Am. Chem. Soc., 2017, 139, 14518-14525. 
52 X. Ding, Y. Gao, L. Zhang, Z. Yu, J. Liu and L. Sun, ACS Catal., 2014, 4, 2347-2350.

53 B. H. Farnum, K.-R. Wee and T. J. Meyer, Nat. Chem., 2016, 8, 845-852.

54 H. Lee, L. J. Kepley, H. G. Hong and T. E. Mallouk, J. Am. Chem. Soc., 1988, 110, 618-620.

55 B. H. Farnum, K.-R. Wee and T. J. Meyer, Nat. Chem., 2016, 8, 845.

56 B. Shan, B. D. Sherman, C. M. Klug, A. Nayak, S. L. Marquard, Q. Liu, R. M. Bullock and T. J. Meyer, J. Phys. Chem. Lett., 2017, 8, 4374-4379.

57 R. Argazzi, C. A. Bignozzi, T. A. Heimer, F. N. Castellano and G. J. Meyer, Inorg. Chem., 1994, 33, 5741-5749.
58 B. Shan, B. H. Farnum, K.-R. Wee and T. J. Meyer, J. Phys. Chem. C, 2017, 121, 5882-5890.

59 Z. Ji, M. He, Z. Huang, U. Ozkan and Y. Wu, J. Am. Chem. Soc., 2013, 135, 11696-11699.

60 S. E. Bettis, K. Hanson, L. Wang, M. K. Gish, J. J. Concepcion, Z. Fang, T. J. Meyer and J. M. Papanikolas, J. Phys. Chem. A, 2014, 118, 10301-10308.

61 M. L. Clark, P. L. Cheung, M. Lessio, E. A. Carter and C. P. Kubiak, ACS Catal., 2018, 8, 2021-2029.

62 C. Riplinger and E. A. Carter, ACS Catal., 2015, 5, 900-908.

63 K. Koike, D. C. Grills, Y. Tamaki, E. Fujita, K. Okubo, Y. Yamazaki, M. Saigo, T. Mukuta, K. Onda and O. Ishitani, Chem. Sci., 2018, 9, 2961-2974. 